\title{
Management of Patients with Patent Foramen Ovale and Cryptogenic Stroke: An Update
}

\author{
Mohammad Abdelghani ${ }^{a-c}$ Sahar A.O. El-Shedoudy ${ }^{d}$ Martina Nassif ${ }^{b}$ \\ Berto J. Bouma ${ }^{\text {b }}$ Robbert J. de Winter ${ }^{\text {b }}$

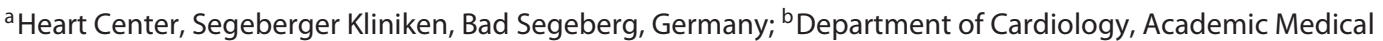 \\ Center, Amsterdam, The Netherlands; ${ }^{\mathrm{C}}$ Department of Cardiology, Al-Azhar University, Cairo, Egypt; ${ }^{\mathrm{d}}$ Department of \\ Cardiology, Tanta University, Tanta, Egypt
}

\section{Keywords}

Patent foramen ovale · Percutaneous closure ·

Transcatheter closure $\cdot$ Cryptogenic stroke

\begin{abstract}
Patent foramen ovale (PFO) is a common benign finding in healthy subjects, but its prevalence is higher in patients with stroke of unclear cause (cryptogenic stroke). PFO is believed to be associated with stroke through paradoxical embolism, and certain clinical and anatomical criteria seem to increase the likelihood of a PFO to be pathological. Recent trials have shown that closure of PFO, especially if associated with an atrial septal aneurysm and/or a large interatrial shunt, may reduce the risk of recurrent stroke as compared to medical treatment. However, it remains challenging to risk stratify patients with suspected PFO-related stroke and to decide if device closure is indicated. We sought to review contemporary evidence and to conclude an evidence-based strategy to prevent recurrence of PFO-related stroke.
\end{abstract}

(c) 2019 S. Karger AG, Basel (c) 2019 S. Karger AG, Basel

\section{E-Mail karger@karger.com}

www.karger.com/crd

\section{Introduction}

Patent foramen ovale (PFO) is a normal interatrial communication during fetal life that commonly persists thereafter [1]. The prevalence of PFO ranges from 25 to $35 \%$, with decreasing prevalence and increasing size with each decade of life, possibly indicating that larger PFOs remain patent and smaller defects close over time $[2,3]$.

During fetal life, the septum primum (a flap that forms the floor of the fossa ovalis) and the septum secundum (an infolding of the atrial wall on the right atrial [RA] side) fuse together [4]. The fusion of both septa is not complete leaving an interatrial communication at the antero-superior edge of the fossa ovalis (the site of the embryonic ostium secundum) which constitutes the foramen ovale. This communication allows blood from the inferior caval vein - directed preferentially to the foramen ovale by the Eustachian valve - to bypass the pulmonary circulation into the left heart. Following decreased pulmonary resistance and increased left atrial (LA) pressure at birth, the septum primum adheres to the fossa

Dr. Mohammad Abdelghani Heart Center, Segeberger Kliniken Am Kurpark 1

DE-23795 Bad Segeberg (Germany)

E-Mail m.abdelghani.nl@gmail.com 
ovalis rim, and obliteration of the foramen ovale is usually complete by the first year of life [5].

The PFO diameter (average, $4.9 \mathrm{~mm}$ ) allows the passage of emboli from the venous system that are large enough to occlude up to the middle cerebral artery stem $(3 \mathrm{~mm})$ to reach the cerebral circulation [6]. Each year, 345,000 patients aged 18-60 years present with a PFO and an embolic stroke of otherwise undetermined source worldwide [6]. Younger patients with a cryptogenic stroke have a 2.3-fold increased relative risk of having a PFO, compared with age-matched individuals with a stroke of a clear cause, suggesting - based on probability theory - a 73\% likelihood that PFO is the mechanism of the stroke in those patients [6]. Based on transesophageal echocardiographic (TEE) screening, patients with a cryptogenic stroke/transient ischemic attack (TIA) have an average prevalence of any PFO, PFO associated with atrial septal aneurysm (ASA), and large $\mathrm{PFO}$ of $43.2 \%, 14.5 \%$, and $19.5 \%$, respectively. Importantly, the prevalence of any PFO, PFO with septal aneurysm, and large PFO showed a remarkable variability between younger ( $<50$ years) versus older patients: $59.9 \%$ vs. $35.2 \%, 16.3 \%$ vs. $11.6 \%$, and $18.6 \%$ vs. $22.9 \%$, respectively; suggesting that PFOs tend to close over time, with larger PFOs tending to persist into older age [7].

\section{Anatomy and Morphology of PFO: Pathologic and Therapeutic Implications}

Since the flap valve of the fossa ovalis (made by the septum primum) is larger than the fossa, the length of the overlap between both septae can be considerable, resulting in a tunnel-like PFO with a length (depth) of 1-6 mm (longer variants are uncommon), a width of 5-13 $\mathrm{mm}$ (average $4.9 \mathrm{~mm}$ ), and RA aperture measuring 6-9 $\mathrm{mm}$ at the long axis and $3-6 \mathrm{~mm}$ at the short axis $[3,5,8]$. The tunnel has RA entrance at the antero-superior edge of the fossa ovalis and LA exit located close to the antero-superior LA wall towards the aorta [5]. This proximity to the atrial wall should be carefully considered when attempting to advance a catheter through a long PFO which could penetrate through the atrial wall which is usually exceptionally thin at this location [5] (Fig. 1).

A long narrow tunnel is one morphological form of PFO, but the morphology of PFOs varies considerably between individuals and can be broadly classified into simple and complex. Criteria of complex PFO include: long tunnel length ( $\geq 8 \mathrm{~mm})$, ASA, thick septum secundum ( $\geq 10 \mathrm{~mm})$, very short septum secundum flap (i.e., short/absent aortic rim), and prominent Eustachian ridge or Eustachian valve
[5]. A complex PFO is more likely associated with cryptogenic stroke and may require special considerations when choosing the type and size of the occluder device.

\section{Pathophysiology of PFO-Related Ischemic Stroke}

Brain infarction not attributed to arteriosclerosis, small vessel disease, or cardio-embolism after extensive vascular, serologic, and cardiac evaluation (cryptogenic stroke [9]) constitutes up to $40 \%$ of all ischemic strokes [10,11]. An association between PFO and cryptogenic stroke has been established in the 80s of the last century [12-14]. Paradoxical embolism is the suggested mechanism linking PFO to stroke and occurs when a thrombus from the systemic venous circulation passes to the systemic arterial circulation via a right-to-left shunt. The concept of paradoxical embolism through a PFO was first described by Zahn in 1881 who described a branched thrombus from a uterine vein caught in a PFO on a postmortem examination [10]. In patients with cryptogenic stroke, the rates of deep venous thrombosis (20 vs. $4 \%$ ) and PFO (59 vs. 19\%) are higher than in patients with stroke of known origin [15]. Besides paradoxical embolism, the combination of a large PFO with ASA has been suggested to lead to LA dysfunction producing an "atrial fibrillation (AF)-like" pathophysiology predisposing to systemic thromboembolism that normalizes after PFO device closure [16]. PFO should be differentiated from LA septal pouch, which is a different, albeit related, entity that has been controversially linked to cryptogenic stroke $[17,18]$. Defined as a diverticulum on the left side of the interatrial septum exclusively connected to the LA in the absence of an interatrial communication $[18,19]$, the LA septal pouch has been shown to serve as a site of stasis and thrombus formation [20] but has also been linked to an increased AF risk [21].

Although labeling a stroke attributable to paradoxical embolism as "cryptogenic" could be seen as a misnomer [22] as the cause of the stroke is already known, this terminology prevails in the medical literature to date and will be applied throughout this report to describe stroke with no obvious cause other than PFO-related embolism.

\section{Confirming a Causal Relationship between PFO and Stroke Is Challenging}

In spite of the strong evidence suggesting an association between PFO and the risk of stroke, confirming a causal relationship in a given patient is challenging. Even in those 

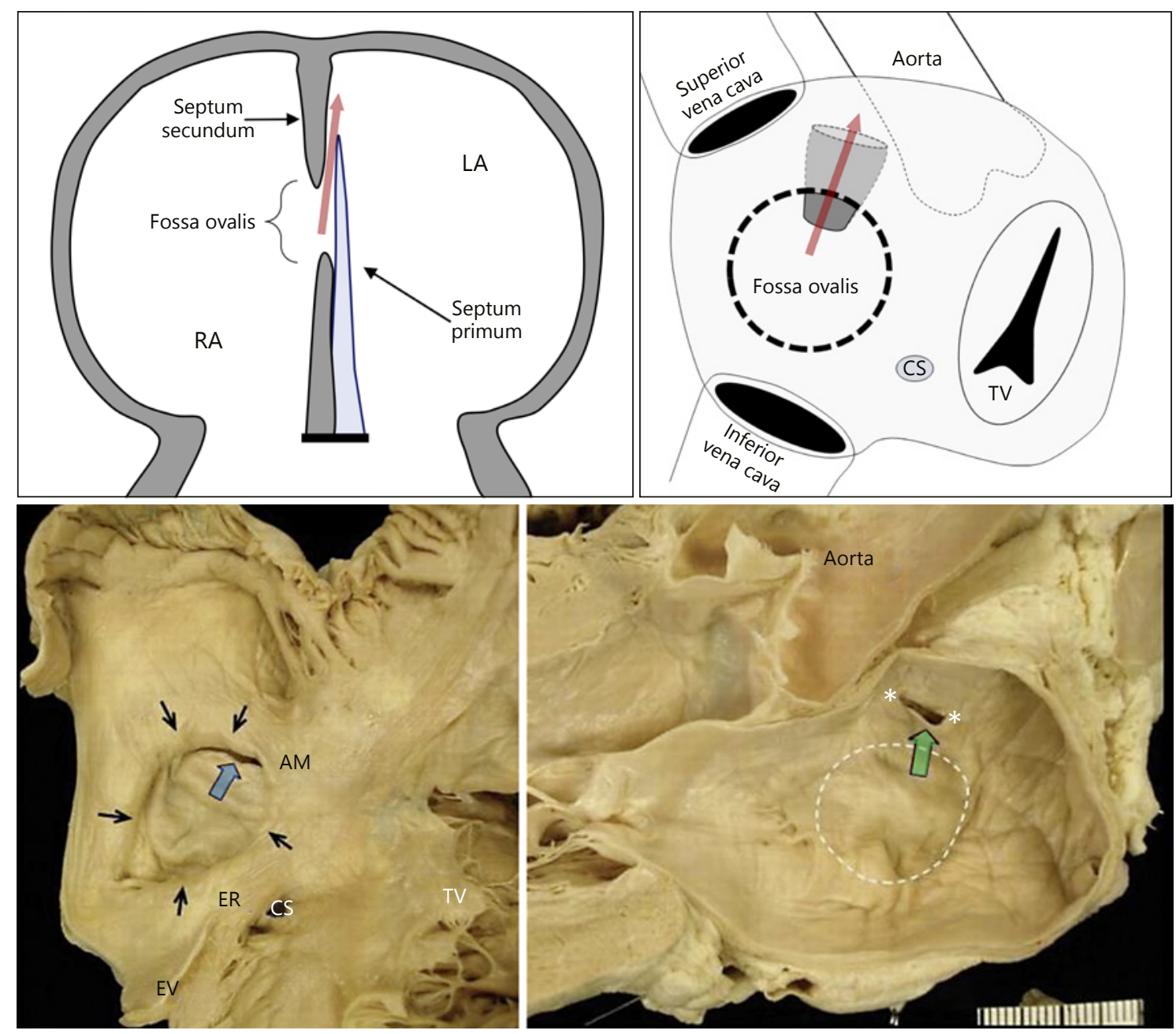

Fig. 1. The right atrial entrance (blue arrow in the lower left panel) and the left atrial exit (green arrow and white asterisks in the lower right panel) of a patent foramen ovale tunnel (red arrows in upper panels). The left atrial exit is located close to the antero-superior atrial wall predisposing the atrial wall to penetration if a catheter is advanced through a long PFO tunnel. The raised margin of the fossa ovalis is shown in the lower left panel (black arrows).
Upper left panel: diagrammatic transection through the embryonic atrial septum. Upper right and lower left panels: right atrial view. Lower right panel: left atrial view. AM, aortic mound; CS, coronary sinus; ER, Eustachian ridge; EV, Eustachian valve; LA, left atrium; RA, right atrium; TV, tricuspid valve. Lower panels reproduced with permission from Rana et al. [5]. with cryptogenic stroke, at least one third of PFOs discovered are likely to be incidental [23]. In those cases, closure of an incidental PFO would expose patients to procedural and device-related risks while leaving the actual cause of stroke unaddressed. The probability that stroke is actually attributable to PFO is higher in younger than in older patients [23], in the absence of clinical risk factors for stroke than in the presence of such risk factors [24], and in case of a cortical infarct (suggesting an embolic mechanism) [25]. Notwithstanding, the association between PFO and stroke risk has been documented - albeit less strongly - in older patients and in patients with classical stroke risk factors, as well as in non-cortical brain infarcts [26-28]. The presence of ASA (seen in approximately $30 \%$ of PFO cases [29]) also increases the likelihood that PFO is implicated in stroke [23] as well as the risk of recurrent stroke [30]. ASA may hemodynamically facilitate access of venous emboli arriving in the RA into a PFO or cause local thrombosis in the PFO tunnel or the atria (by inducing flow turbulence and/or stagnation) [31].

Additionally, a causal relationship between PFO and stroke is more likely in the presence of larger PFOs (de- 
Fig. 2. Estimating the probability of a patent foramen ovale (PFO) being embolism related. This risk stratification is based on patient's clinical profile, brain infarct pattern, anatomical PFO features, and conditions potentially predisposing to/precipitating paradoxical embolism through PFO. RoPE, risk of paradoxical embolism; VTE, venous thromboembolism.

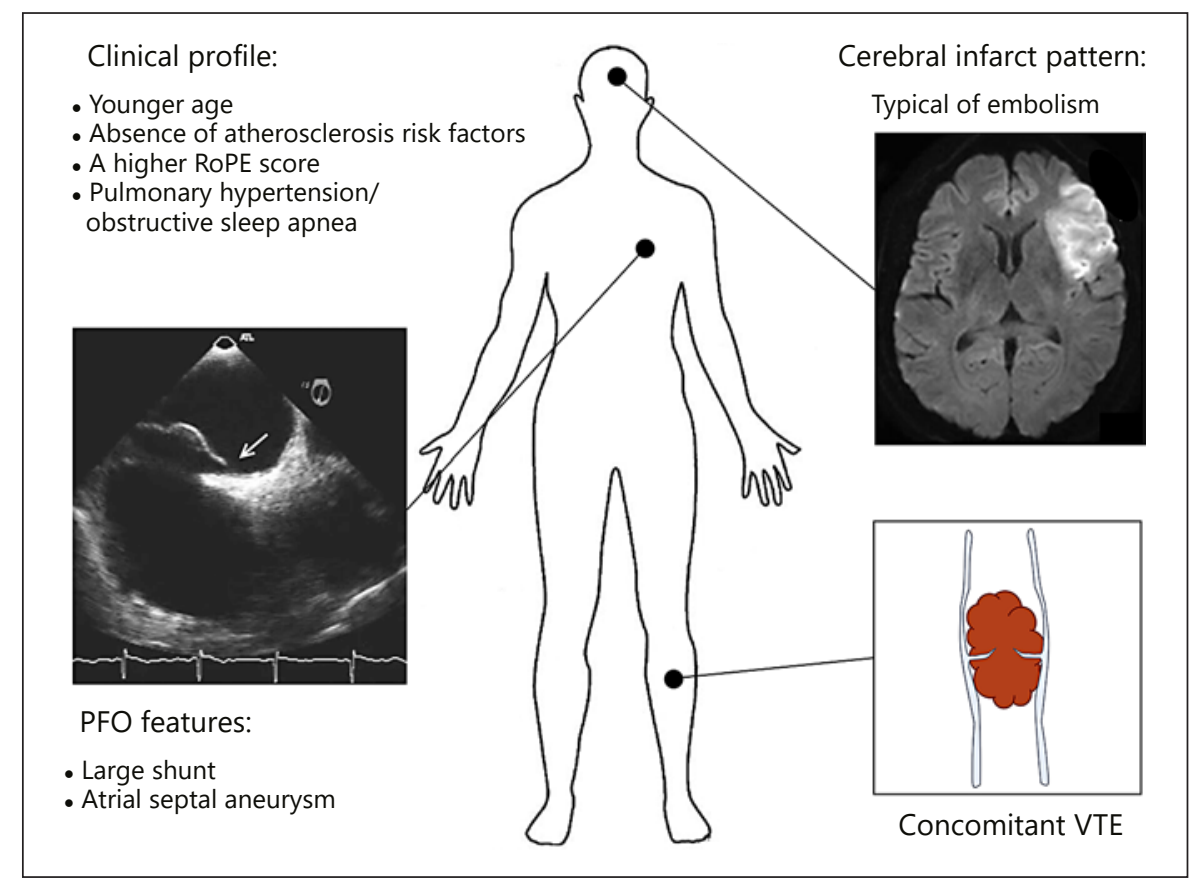

fined as the maximum separation of the septum primum and septum secundum $\geq 2 \mathrm{~mm}$ ), longer tunnel length (defined as a maximum overlap of the septum primum and septum secundum $\geq 8 \mathrm{~mm}$ ), and/or severe shunting (defined as $>30$ microbubbles on contrast echocardiography) $[32,33]$. Another clinical clue suggesting paradoxical embolism in the presence of PFO is concomitant venous thromboembolism (VTE) [34]. Other less-wellestablished factors predisposing to paradoxical embolism in the setting of PFO include straining pre-stroke, waking up with a TIA or stroke, and obstructive sleep apnea [35]. Accordingly, the risk criteria for stroke in patients with a PFO can be broadly categorized into clinical criteria (at the patient level), PFO anatomical/functional criteria, cerebral imaging criteria, and circumstantial criteria (e.g., concomitant VTE or straining pre-stroke) (Fig. 2).

The RoPE (risk of paradoxical embolism) score combines some of these criteria to identify stroke-related versus incidental PFO in cryptogenic stroke [24]. The 10 -point score is calculated from the following variables: younger age, the presence of a cortical stroke on neuroimaging, and the absence of diabetes, hypertension, smoking, and prior stroke or TIA. The youngest patients with superficial strokes and without atherosclerosis risk factors have the highest score indicating a higher likelihood that PFO is stroke-related rather than incidental. Although helpful and practical, the RoPE score should always be used in conjunction with other parameters be- cause it is only modestly validated and does not account for high-risk morphological features of the PFO [22]. Among few external validation studies, one small study identified a RoPE score $>7$ as a cutoff point indicating that PFO is more likely to be stroke related [36]. In another study of a cryptogenic stroke cohort, the prevalence of PFO-related right-to-left shunt was $50-56 \%$ in patients with RoPE scores $<7$ vs. $79 \%$ in those with a score $\geq 7$ [37]. Additionally, a higher RoPE score correlated modestly with the severity of right-to-left shunt [37]. Other studies use a score $>5$ [38] or $>6$ [39] to classify PFO as stroke related.

\section{Risk Stratification and Preclosure Workup}

\section{Cryptogenic Stroke Workup}

PFO closure is typically and most commonly considered in patients with otherwise cryptogenic stroke after a careful exclusion of potential causes of ischemic stroke through brain, aortic, and carotid imaging, cardio-embolic screening, as well as screening for thrombophilia. Even when aortic, cervical, and cerebral vessel imaging does not identify large artery atherosclerosis, the presence of atherosclerosis risk factors per se diminishes the likelihood that PFO is causally related to the index stroke. As ischemic stroke is much more commonly due to LA appendage thrombosis than due to paradoxical embolism, 
identifying AF is important before a stroke is ascribed to PFO. Routine 12-lead ECG and either inpatient cardiac telemetry or 72 -h Holter monitoring are indicated in all cases, and insertable cardiac monitors for $\geq 6$ months are indicated in AF high-risk patients (e.g., older age, diabetes, heart failure, LA hypertrophy, and prolonged PR interval) to rule out AF before deciding upon PFO closure $[22,31]$.

\section{Demonstration and Quantification of a Right-to-Left Shunt}

In order to implicate a PFO as a cause of stroke, a rightto-left shunt must be demonstrated, for example, by contrast echocardiography using saline microbubble or dedicated echo contrast media. In saline contrast echocardiography, an agitated mixture of $5-10 \mathrm{~mL} 0.9 \%$ saline and $0.2-1 \mathrm{~mL}$ air \pm small amount of patient's own blood (to improve echogenicity) is inspected carefully for visible bubbles - which must be discarded - and injected through a large-bore intravenous cannula placed in the left arm and/or in the lower limb (in case of a negative study in spite of high clinical suspicion).

As right-to-left shunting occurs only when RA pressure exceeds LA pressure, maneuvers such as the Valsalva maneuver, sniffing, or coughing are usually required to demonstrate the shunt. To prove efficiency of such maneuvers, thus enabling confident $\mathrm{PFO}$ exclusion, the septum primum should be seen to deviate/bounce towards the LA at the time when the RA is completely filled with contrast. A bubble contrast study should be performed during transthoracic echocardiography (TTE) when the patient can actively perform the provocative maneuvers, and - if necessary - be repeated during TEE. A potential pitfall is the difficulty in distinguishing a pulmonary shunt from a cardiac shunt (usually appears within 3 cardiac cycles from RA opacification). Standardized grading of the severity of the shunt is based on the maximum number of bubbles seen within the LA in a single frame within 3 cardiac cycles after RA opacification, with $>25-30$ bubbles typically indicating a severe shunt $[22$, 40]. In patients with inadequate echocardiographic images as well as in those with a negative TTE in spite of high clinical suspicion, detection of shunt with provocation can be alternatively performed using contrast-enhanced transcranial Doppler (TCD), typically involving a unilateral interrogation of the middle cerebral artery. On TCD, the detection of $>10$ high-intensity transient signals after intravenous injection of agitated saline \pm blood suggests the presence of a severe right-to-left shunt. In addition to the bubble test with provocation, another less-applied ap-
Table 1. PFO morphologic information required for risk stratification and therapeutic decision making

Essential parameters derived from 2D TTE and TEE

- PFO morphology: size, location, length of the tunnel, and maximum separation of the septum primum from the septum secundum

- Comprehensive evaluation of the atrial septum, including: (a) assessment of the thickness of the septum primum and secundum,

(b) assessment of septal motion and in-/exclusion of atrial septal aneurysm, and

(c) exclusion of other atrial septal defects/abnormalities

- Spatial relationship and distance between the PFO inlet and exit and the aortic root, vena cava, valves, and the free atrial wall

- Presence/absence of prominent Eustachian valve/ridge and/ or Chiari network

Supplementary parameters derived from $3 D$ TEE

- Size of right and left atrial openings

- Assessment of the width and confirmation of the length of the PFO tunnel

- Detection of multiple openings of the PFO into the left atrium

proach is 30-min monitoring for spontaneous micro-embolism. Each of the aforementioned tools has its relative advantages and disadvantages. For example, taking TEE as a reference, TCD is more sensitive (reliable in ruling out $\mathrm{PFO}$ ) but less specific (less reliable in ruling in $\mathrm{PFO}$ ) as compared to TTE [41].

After demonstration of a right-to-left shunt (by contrast echocardiography and/or contrast TCD), TEE is necessary to define PFO anatomy and to exclude the presence of other potential sources (e.g., aortic arch atherosclerosis, atrial appendage thrombi, and other shunts such as atrial septal defect, unroofed coronary sinus, and pulmonary arteriovenous malformations).

\section{Assessment of PFO Morphology}

After confirmation of a PFO-related right-to-left shunt, other shunts are excluded, and shunting through the PFO is indicted for paradoxical embolism, further characterization of PFO is necessary before a closure procedure is undertaken (Table 1). On the one hand, certain morphologic features increase the likelihood that PFO is pathological, and, on the other hand, some of the anatomical features are important for deciding upon the feasibility of transcatheter closure as well as the choice of the device type and size. For example, an excessively mobile septum might call for a larger device diameter to secure anchorage, and an excessively thick septum secundum
Abdelghani/El-Shedoudy/Nassif/Bouma/ de Winter 
(e.g., $\geq 10 \mathrm{~mm}$ ) may prevent the device disks from resting flush against the fossa ovalis calling for a smaller device size and/or a softer device platform (e.g., the NMT Medical Biostar) [5]. While PFO/atrial septal anatomical features can be determined on preprocedural echocardiography, evaluation can sometimes be completed only during the procedure when a catheter is introduced through the PFO tunnel pushing the septal flap aside, thus allowing further appreciation of the dimensions and flexibility of the PFO tunnel.

\section{Treatment of Stroke-Indicted PFO}

\section{Therapeutic Options}

Medical Treatment. From a pathophysiological standpoint, anticoagulation might be superior to antiplatelet therapy in preventing PFO-related stroke, as anticoagulants better prevent thrombi arising in veins. However, anticoagulation is also associated with increased bleeding, and comparative studies have shown only modest evidence of an efficacy advantage [6].

In most studies, oral anticoagulant (OAC) therapy was based on vitamin Kinhibitors, while direct OACs were used in few trials. Antiplatelet therapy applied in clinical trials is variable, consisting of acetylsalicylic acid, clopidogrel, and/ or extended-release dipyridamole. Currently available evidence suggests that OAC may be superior to antiplatelet therapy [42-47] and that device closure plus antiplatelet therapy may not be superior to $\mathrm{OAC}$ for secondary prevention of PFO-related stroke $[6,45]$. However, the risk of major bleeding is higher with OAC $[22,48]$, and the hemorrhagic risk could be reduced with the use of direct OACs [49], although few robust data exist in PFO patients [42].

Percutaneous Closure. Most contemporary evidence on PFO closure has been obtained with the Amplatzer PFO occluder, the use of which has been shown to be associated with a higher complete closure rate and a relatively lower risk of $\mathrm{AF}$ as compared to other contemporary occluders [22]. To date, two PFO closure devices received FDA approval: the Amplatzer PFO occluder (in October 2016) and the GORE CARDIOFORM septal occluder (in March 2018).

Complete occluder endothelialization can take up to 5 years after implantation. Therefore, dual antiplatelet therapy is recommended for 1-6 months after PFO closure, and single antiplatelet therapy thereafter for at least 5 years [22].

PFO closure is generally a relatively safe procedure and PFO closure-related complications are estimated to occur in $2.6 \%$ of cases in randomized trials [22, 50, 51]: Possible complications include a residual shunt, atrial arrhythmias, and, rarely, device thrombosis, embolization, endocarditis, and erosion. Pericardial effusion can occur as a result of intraprocedural perforation, acute/delayed device erosion, and/or allergic reaction (usually mild effusion).

Most of these complications, as well as the risk of a residual shunt and recurrent thromboembolic events are relatively less frequent with the Amplatzer PFO occluder compared to other commercially available devices [22, 50-52].

$\mathrm{AF}$ is the most frequent complication of percutaneous closure. In a recent meta-analysis $(n=3,924$ patients; mean follow up $=2.8 \pm 1.7$ years), $\mathrm{PFO}$ closure was associated with an increased risk of new-onset AF compared to medical therapy (relative risk: $4.30,95 \%$ CI: $2.40-7.90$ ). However, the majority of device-associated AF (76\%) occurred early, did not recur, and were associated with a very small number of stroke events presumably attributable to device-associated AF [53]. The risk of AF appears to be lower with the Amplatzer PFO occluder than other devices used in large-scale trials [22].

\section{PFO Closure: History and Current Evidence}

The first patient series of device PFO closure for presumed paradoxical embolism was reported in 1992 by Bridges et al. [54]. Since then, many investigators sought to prove the feasibility, safety, and efficacy of PFO closure to prevent recurrent stroke. In a meta-analysis of the relatively small retrospective studies published until 2003 [55], the 1-year recurrence rate of neurological events was $0-4.9 \%$ for device closure (1,355 patients in 10 studies) compared with $3.8-12 \%$ for medical therapy (895 patients in 6 studies). The results of this meta-analysis were then further supported by another relatively large - yet single-center, retrospective - study which showed that at the 4-year follow-up, PFO device closure resulted in a reduction in the incidence of recurrent stroke or TIA compared to medical therapy [55]. Those studies, and others, have stimulated the conduction of a number of prospective randomized trials comparing PFO device closure to medical treatment in patients with $\mathrm{PFO}$ and otherwise cryptogenic stroke.

In 2012-2013, the results of the first large-scale randomized trials of PFO closure were published. The CLOSURE I trial [56] ( $n=909$ patients) randomized patients with otherwise cryptogenic stroke or TIA and had a PFO 
to percutaneous closure (with the STARFlex device [NMT Medical] combined with dual antiplatelet therapy for 6 months and aspirin for further 18 months) or medical (antiplatelet and/or anticoagulant) therapy alone. The rate of stroke or TIA during 2 years of follow-up was 5.5\% in the closure group versus $6.8 \%$ in the medical-therapy group ( $p=0.37)$. The $\mathrm{PC}$ trial $(n=414$ patients) compared transcatheter closure (using the St. Jude medical Amplatzer PFO occluder combined with dual antiplatelet therapy for 1-6 months) versus medical therapy (comprising antiplatelet or anticoagulant therapy) [57]. At a mean follow up of 4.1 years, PFO closure did not result in a significant reduction in the risk of recurrent embolic events or death as compared with medical therapy (3.4 vs. $5.2 \%, p=0.34)$. The RESPECT trial ( $n=980$ patients) compared transcatheter closure (using the Amplatzer PFO occluder combined with dual antiplatelet therapy for 1 month followed by aspirin for 5 months) with medical therapy (antiplatelet[s] or warfarin) [58]. The primary endpoint of recurrent ischemic stroke or early death occurred in 1.8 versus $3.3 \%$ in the device closure versus medical treatment arms, respectively (HR $0.49,95 \%$ CI $0.22-1.1, p=0.08$ ). Owing to a higher dropout rate in the medical-therapy group, treatment exposure between both groups was unequal. In the as-treated analysis, closure was significantly superior to medical therapy regarding the rate of recurrent stroke at $2.6 \pm 2.0$ years of followup.

Most of the early randomized trials of PFO closure did not meet the primary endpoint, likely due to a combination of poor enrollment, relatively short follow-up, lenient inclusion criteria with modest proportion of PFOs with high-risk features (large shunt and/or ASA), and a relatively high rate of residual shunt and device thrombosis of the older device designs. This has led to raising the awareness of the design that would be most appropriate for future trials and suggested that patients with anatomical high-risk features of PFO (ASA/large shunt) are probably the patient group most likely to benefit from PFO closure. Data have also suggested that to demonstrate a clear advantage of PFO closure over medical treatment for secondary prevention of stroke, a longerterm follow-up is required. Recently (as of 2017), the results of multiple randomized trials involving a relatively long follow-up and applying more strict features for patient inclusion were published.

RESPECT Trial. The long-term follow-up results of the RESPECT trial (median follow-up of 5.9 years) further confirmed that PFO closure is associated with a lower rate of recurrent ischemic strokes than medical therapy alone (HR 0.55, 95\% CI 0.30-1.0, $p=0.046$ ) [59]. On sensitivity analysis, superiority of PFO closure was shown to be significant only in those with ASA (as compared to no ASA) and in those with a severe shunt (as compared to those with a moderate or less severe shunt). Importantly, the rate of recurrent ischemic stroke of undetermined mechanism was significantly lower after PFO closure than with medical therapy, while the rate of recurrent ischemic strokes of determined mechanism was not different between both groups.

CLOSE Trial. The CLOSE trial ( $n=663$ patients) included patients with a recent stroke attributed to $\mathrm{PFO}$ with an associated ASA or large interatrial shunt [45]. Patients were randomized to transcatheter PFO closure (with any Conformité Européenne [CE]-marked device) plus dual antiplatelet therapy for 3 months followed by aspirin for life, antiplatelet therapy alone, or OAC. At a mean follow-up of $5.3 \pm 2.0$ years, the incidence of recurrent stroke was significantly lower ( 0 vs. $4.9 \%$, HR $0.03,95 \%$ CI $0-0.26, p<0.001$ ) while the rate of AF was higher in the PFO closure than in the antiplatelet-only group. In the anticoagulation group, $20 \%$ of patients discontinued the anticoagulation therapy and no significant difference in the rate of recurrent stroke was observed between this group and the antiplatelet only group.

GORE REDUCE Trial. In the GORE REDUCE trial [60] ( $n=664$ patients), patients were randomized to undergo PFO closure (using the GORE CARDIOFORM septal occluder or GORE HELEX septal occluder [GORE and Associates]) plus antiplatelet therapy or antiplatelet therapy alone. Notably, ASA was not routinely checked for, and $81 \%$ of enrolled patients had a moderate-severe shunt. During a median follow-up of 3.2 years, the incidence of clinical ischemic stroke was significantly lower in the PFO closure group as compared to the antiplateletonly group (1.4 vs. $5.4 \%$, HR $0.23,95 \%$ CI $0.09-0.62, p=$ $0.002)$. In the PFO closure group, AF occurred in $6.6 \%$ of patients.

DEFENSE-PFO Trial. In this trial ( $n=120$ patients), patients with cryptogenic stroke and high-risk PFO (defined as PFO with ASA or septal hypermobility, or large $\mathrm{PFO}$, i.e., maximum separation of the septum primum from the secundum $\geq 2 \mathrm{~mm}$ ) were randomized to transcatheter PFO closure with the Amplatzer occluder or medical treatment (as decided by the treating physician). During the 2-year follow-up, the primary endpoint (a composite of stroke, vascular death, or major bleeding) occurred exclusively in the medical treatment group (12 vs. $0 \%)[61]$.
68

Cardiology 2019;143:62-72 DOI: $10.1159 / 000501028$
Abdelghani/El-Shedoudy/Nassif/Bouma/ de Winter 
Table 2. Features of PFO closure device trials

\begin{tabular}{|c|c|c|c|c|c|c|c|c|}
\hline $\begin{array}{l}\text { Study/publication, } \\
\text { year }\end{array}$ & Patients, $n$ & $\begin{array}{l}\text { Mean } \\
\text { follow-up, } \\
\text { years }\end{array}$ & $\begin{array}{l}\text { ECG rhythm } \\
\text { monitoring }\end{array}$ & $\begin{array}{l}\text { Age, } \\
\text { years }\end{array}$ & $\begin{array}{l}\text { Large shunt/ } \\
\text { ASA, \% }\end{array}$ & $\begin{array}{l}\text { OAC in } \\
\text { medical } \\
\text { arm, } \%\end{array}$ & $\begin{array}{l}\text { Double disk } \\
\text { device, } \%\end{array}$ & $\begin{array}{l}\text { Effective } \\
\text { closure, \% }\end{array}$ \\
\hline PC, 2013 & 414 & 4.1 & 12 lead & 44 & $19 / 24$ & 21 & $100^{\mathrm{c}}$ & 96 \\
\hline RESPECT, 2013/2017 & 980 & 5.8 & 12 lead & 46 & $49 / 36$ & 22 & $100^{c}$ & 94 \\
\hline REDUCE, 2017 & 664 & 3.4 & 12 lead & 45 & $39 / 20$ & 0 & $100^{\mathrm{d}}$ & 95 \\
\hline DEFENSE-PFO, 2018 & 120 & 1.6 & Holter/prolonged & $49 / 54$ & $\mathrm{NR} / 57^{\mathrm{a}}$ & 22 & $100^{\mathrm{c}}$ & 94 \\
\hline
\end{tabular}

${ }^{a}$ In the DEFENSE-PFO trial, at least 1 high-risk PFO criterion (ASA, septal hypermobility, or large PFO) was required for inclusion. ${ }^{b}$ STARFlex septal occluder (NMT Medical). ${ }^{\mathrm{c}}$ The St. Jude medical Amplatzer PFO occluder. ${ }^{\mathrm{d}}$ GORE CARDIOFORM septal occluder or GORE HELEX septal occluder (GORE and Associates). ${ }^{\mathrm{e}}$ Any CE marked device was acceptable.

Features of the 6 randomized PFO closure trials (collectively comprising 3,740 patients and a total of 13,850 patient-years follow-up) are summarized in Table 2.

Meta-Analysis of Randomized Trials. In 2 meta-analyses by De Rosa et al. [62] and Shah et al. [63], data from 4 randomized trials (PC, RESPECT, REDUCE, and CLOSE) were pooled. Both the CLOSURE I trial (involving a device that is no longer available) and the DEFENSE-PFO trial (published after conduction of the meta-analyses) were not included. Both meta-analyses showed that PFO closure prevents recurrent stroke but increases the incidence of $\mathrm{AF}$ as compared to medical treatment. PFO closure was associated with a stroke risk reduction of 3.1-3.3\% [62, 63] and new-onset AF/flutter risk increment of $3.3 \%$ [62].

\section{Conclusions}

\section{Contemporary Evidence-Based Management of PFO}

As discussed above, recent trials have shown that PFO closure is superior to medical treatment in the secondary prevention of ischemic stroke especially when performed in a specific PFO patient group (18-60 years old) characterized by: (a) likely otherwise cryptogenic stroke and (b) high-risk PFO features (e.g., ASA and large shunt). On the other hand, older trials which tended to be negative mostly enrolled unselected patients without high-risk PFO features and sometimes without exhaustive confirmation of otherwise cryptogenic stroke. Therefore, it is very important to underline the importance of patient selection for PFO closure, bearing in mind that not all patients with apparently PFO-related embolism will clearly benefit from percutaneous closure. The estimated num- ber needed to treat with $\mathrm{PFO}$ closure to prevent 1 stroke over 5 years is 24 in unselected patients and 13 in patients with ASA [6]. Notwithstanding, it should be borne in mind that an even modest annual stroke risk reduction will likely pile up over many future at-risk years in younger patients with first cryptogenic ischemic stroke. Moreover, a markedly higher incidence of PFO-related stroke in certain situations of increased stroke risk (e.g., after operation in PFO patients undergoing non-cardiac surgery) may account for an even higher potential benefit of PFO closure in selected patient populations $[64,65]$.

Based on currently available evidence, a European position paper on the management of patients with PFO has recently been published [22]. This position paper recommended the choice of a treatment strategy for PFO in the setting of left circulation thromboembolism based on the following considerations:

Estimating the probability of a PFO being embolismrelated based on the presence of certain patient characteristics, brain infarct patterns, PFO anatomical features, and conditions potentially predisposing to/precipitating paradoxical embolism through a PFO (summarized in Fig. 2).

The expected efficacy and risks of a lifelong medical therapy (as opposed to PFO closure). For example, patients with $\mathrm{AF}$ who require and can tolerate life-long OAC will probably benefit less from device closure than patients who otherwise do not have an indication for $\mathrm{OAC}$ or those with absolute/relative contraindication to prolonged antithrombotic treatment (e.g., planned pregnancy or surgery).

Estimating the risk of recurrence of paradoxical embolism through a PFO. The importance of this risk estimation is that the risk of a recurrent embolism in unselected 
Fig. 3. A suggested management scheme for the prevention of recurrent stroke in patients with first ischemic stroke likely attributable to a patent foramen ovale (PFO). ASA, atrial septal aneurysm; APT, antiplatelet therapy; OAC, oral anticoagulant therapy; RoPE, risk of paradoxical embolism; VTE, venous thromboembolism.

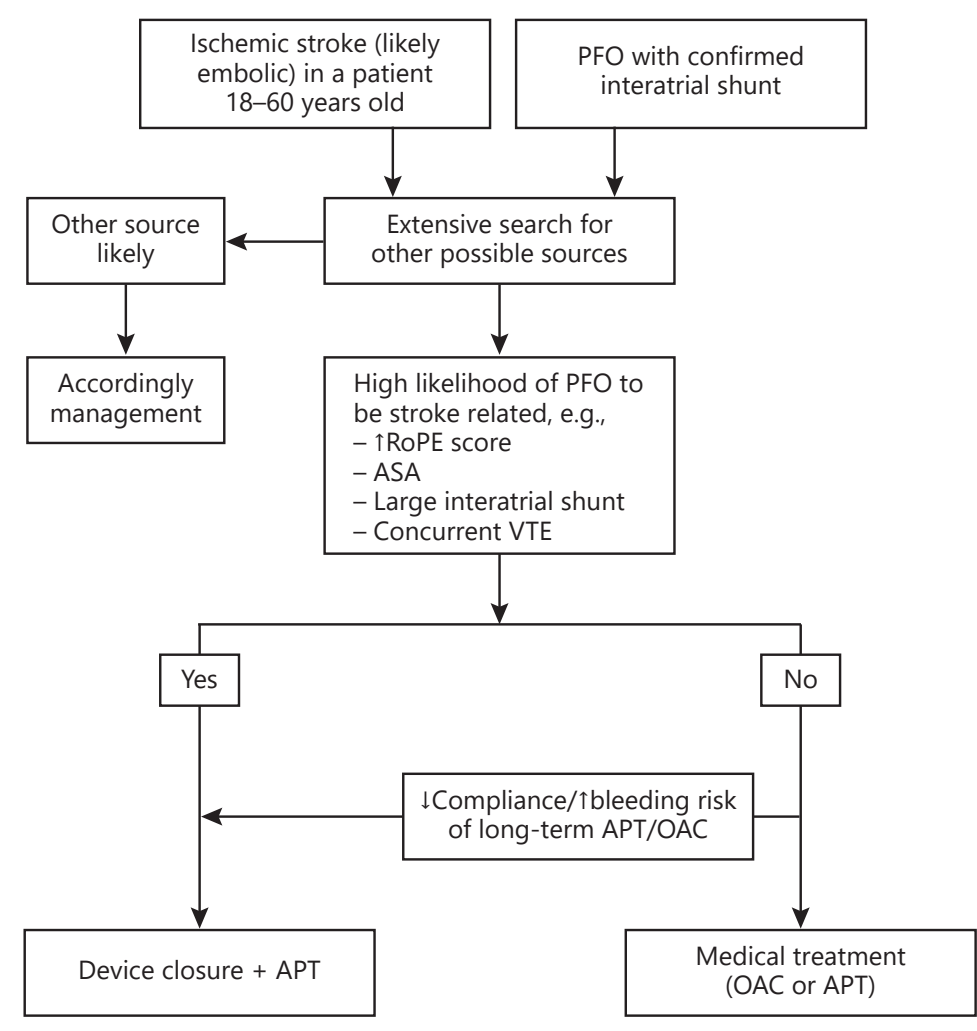

ratio if treated medically are likely to benefit most from PFO closure. PFO closure is to be followed by dual antiplatelet therapy for 1-6 months and single antiplatelet therapy for up to 5 years thereafter. Caution should be exercised as those patients age and acquire new ischemic stroke risk factors (e.g., atherosclerosis risk factors and $\mathrm{AF}$ ), leading to a re-rise in the risk of recurrent stroke that is not attributable to PFO. Therefore, a life-long antithrombotic treatment in spite of PFO closure should be (re)considered on an individual basis. In patients not fulfilling the criteria justifying percutaneous closure, the choice of medical treatment should be individualized according to benefit/risk ratios. Long-term OAC may be an option in patients with: (a) a low bleeding risk, (b) a high likelihood of therapeutic compliance and proper anticoagulant monitoring, and (c) a history of VTE and/or a high risk of stroke recurrence. In patients in whom these conditions are not satisfied, antiplatelet therapy should be prescribed. In cases who are not eligible for device closure, patients should be reassured that the absolute stroke recurrence rate is still low under medical treatment. A suggested management scheme is outlined in Figure 3 and is best implemented by a multidisciplinary team comprising at least a cardiologist and a neurologist. 


\section{References}

1 Geva T, Martins JD, Wald RM. Atrial septal defects. Lancet. 2014 May;383(9932):192132.

2 Hagen PT, Scholz DG, Edwards WD. Incidence and size of patent foramen ovale during the first 10 decades of life: an autopsy study of 965 normal hearts. Mayo Clin Proc. 1984 Jan; 59(1):17-20.

3 Hara H, Virmani R, Ladich E, Mackey-Bojack S, Titus J, Reisman M, et al. Patent foramen ovale: current pathology, pathophysiology, and clinical status. J Am Coll Cardiol. 2005 Nov;46(9):1768-76.

4 Jensen B, Spicer DE, Sheppard MN, Anderson RH. Development of the atrial septum in relation to postnatal anatomy and interatrial communications. Heart. 2017 Mar;103(6): 456-62.

5 Rana BS, Shapiro LM, McCarthy KP, Ho SY. Three-dimensional imaging of the atrial septum and patent foramen ovale anatomy: defining the morphological phenotypes of patent foramen ovale. Eur J Echocardiogr. 2010 Dec;11(10):i19-25.

6 Saver JL, Mattle HP, Thaler D. Patent Foramen Ovale Closure Versus Medical Therapy for Cryptogenic Ischemic Stroke: A Topical Review. Stroke. 2018 Jun;49(6):1541-8.

7 Katsanos AH, Bhole R, Frogoudaki A, Giannopoulos S, Goyal N, Vrettou AR, et al. The value of transesophageal echocardiography for embolic strokes of undetermined source. Neurology. 2016 Sep;87(10):988-95.

8 Ho SY, McCarthy KP, Rigby ML. Morphological features pertinent to interventional closure of patent oval foramen. J Interv Cardiol. 2003 Feb;16(1):33-8.

9 Horlick E, Kavinsky CJ, Amin Z, Dean Boudoulas K, Carroll JD, Hijazi ZM, et al. SCAI expert consensus statement on operator and institutional requirements for PFO closure for secondary prevention of paradoxical embolic stroke: the American Academy of Neurology affirms the value of this statement as an educational tool for neurologists. Catheter Cardiovasc Interv. 2019 Apr;93(5):85974.

10 Calvert PA, Rana BS, Kydd AC, Shapiro LM. Patent foramen ovale: anatomy, outcomes, and closure. Nat Rev Cardiol. 2011 Mar;8(3): 148-60.

11 Sacco RL, Ellenberg JH, Mohr JP, Tatemichi TK, Hier DB, Price TR, et al. Infarcts of undetermined cause: the NINCDS Stroke Data Bank. Ann Neurol. 1989 Apr;25(4):382-90.

12 Lechat P, Mas JL, Lascault G, Loron P, Theard M, Klimczac M, et al. Prevalence of patent foramen ovale in patients with stroke. $\mathrm{N}$ Engl J Med. 1988 May;318(18):1148-52.

13 Handke M, Harloff A, Olschewski M, Hetzel A, Geibel A. Patent foramen ovale and cryptogenic stroke in older patients. N Engl J Med. 2007 Nov;357(22):2262-8.

14 Webster MW, Chancellor AM, Smith HJ, Swift DL, Sharpe DN, Bass NM, et al. Patent foramen ovale in young stroke patients. Lancet. 1988 Jul;2(8601):11-2.

15 Cramer SC, Rordorf G, Maki JH, Kramer LA, Grotta JC, Burgin WS, et al. Increased pelvic vein thrombi in cryptogenic stroke: results of the Paradoxical Emboli from Large Veins in Ischemic Stroke (PELVIS) study. Stroke. 2004 Jan;35(1):46-50.

16 Rigatelli G, Aggio S, Cardaioli P, Braggion G, Giordan M, Dell'avvocata F, et al. Left atrial dysfunction in patients with patent foramen ovale and atrial septal aneurysm: an alternative concurrent mechanism for arterial embolism? JACC Cardiovasc Interv. 2009 Jul;2(7): 655-62.

17 Tugcu A, Okajima K, Jin Z, Rundek T, Homma S, Sacco RL, et al. Septal pouch in the left atrium and risk of ischemic stroke. JACC Cardiovasc Imaging. 2010 Dec;3(12):1276-83.

18 Hołda MK, Krawczyk-Ożóg A, Koziej M, Sorysz D, Hołda J, Dudek D, et al. Left-Sided Atrial Septal Pouch is a Risk Factor for Cryptogenic Stroke. J Am Soc Echocardiogr. 2018 Jul;31(7):771-6.

19 Krishnan SC, Salazar M. Septal pouch in the left atrium: a new anatomical entity with potential for embolic complications. JACC Cardiovasc Interv. 2010 Jan;3(1):98-104.

20 Gurudevan SV, Shah H, Tolstrup K, Siegel R, Krishnan SC. Septal thrombus in the left atrium: is the left atrial septal pouch the culprit? JACC Cardiovasc Imaging. 2010 Dec;3(12): 1284-6.

21 Hołda MK, Koziej M, Wszołek K, Pawlik W, Krawczyk-Ożóg A, Sorysz D, et al. Left atrial accessory appendages, diverticula, and leftsided septal pouch in multi-slice computed tomography. Association with atrial fibrillation and cerebrovascular accidents. Int J Cardiol. 2017 Oct;244:163-8.

22 Pristipino C, Sievert H, D’Ascenzo F, Louis Mas J, Meier B, Scacciatella P, et al.; Evidence Synthesis Team; Eapci Scientific Documents and Initiatives Committee; International Experts. European position paper on the management of patients with patent foramen ovale. General approach and left circulation thromboembolism. Eur Heart J. 2018 Oct. https://doi.org/10.1093/eurheartj/ehy649.

23 Alsheikh-Ali AA, Thaler DE, Kent DM. Patent foramen ovale in cryptogenic stroke: incidental or pathogenic? Stroke. 2009 Jul;40(7): 2349-55.

24 Kent DM, Ruthazer R, Weimar C, Mas JL, Serena J, Homma S, et al. An index to identify stroke-related vs incidental patent foramen ovale in cryptogenic stroke. Neurology. 2013 Aug;81(7):619-25.

25 Thaler DE, Ruthazer R, Di Angelantonio E, Di Tullio MR, Donovan JS, Elkind MS, et al. Neuroimaging findings in cryptogenic stroke patients with and without patent foramen ovale. Stroke. 2013 Mar;44(3):675-80.

26 Mazzucco S, Li L, Binney L, Rothwell PM; Oxford Vascular Study Phenotyped Cohort.
Prevalence of patent foramen ovale in cryptogenic transient ischaemic attack and non-disabling stroke at older ages: a populationbased study, systematic review, and metaanalysis. Lancet Neurol. 2018 Jul;17(7): 609-17.

27 Feurer R, Sadikovic S, Esposito L, Schwarze J, Bockelbrink A, Hemmer B, et al. Lesion patterns in patients with cryptogenic stroke with and without right-to-left-shunt. Eur J Neurol. 2009 Oct;16(10):1077-82.

28 Kim BJ, Sohn H, Sun BJ, Song JK, Kang DW, Kim JS, et al. Imaging characteristics of ischemic strokes related to patent foramen ovale. Stroke. 2013 Dec;44(12):3350-6.

29 Dalen JE, Alpert JS. Which Patent Foramen Ovales Need Closure to Prevent Cryptogenic Strokes? Am J Med. 2018 Mar;131(3):2225.

30 Mas JL, Arquizan C, Lamy C, Zuber M, Cabanes L, Derumeaux G, et al.; Patent Foramen Ovale and Atrial Septal Aneurysm Study Group. Recurrent cerebrovascular events associated with patent foramen ovale, atrial septal aneurysm, or both. N Engl J Med. 2001 Dec;345(24):1740-6.

31 Thijs VN, Brachmann J, Morillo CA, Passman RS, Sanna T, Bernstein RA, et al. Predictors for atrial fibrillation detection after cryptogenic stroke: results from CRYSTAL AF. Neurology. 2016 Jan;86(3):261-9.

32 Steiner MM, Di Tullio MR, Rundek T, Gan R, Chen X, Liguori C, et al. Patent foramen ovale size and embolic brain imaging findings among patients with ischemic stroke. Stroke. 1998 May;29(5):944-8.

33 Goel SS, Tuzcu EM, Shishehbor MH, de Oliveira EI, Borek PP, Krasuski RA, et al. Morphology of the patent foramen ovale in asymptomatic versus symptomatic (stroke or transient ischemic attack) patients. Am J Cardiol. 2009 Jan;103(1):124-9.

34 Lapergue B, Decroix JP, Evrard S, Wang A, Bendetowicz D, Offroy MA, et al. Diagnostic Yield of Venous Thrombosis and Pulmonary Embolism by Combined CT Venography and Pulmonary Angiography in $\mathrm{Pa}$ tients with Cryptogenic Stroke and Patent Foramen Ovale. Eur Neurol. 2015;74(1-2): 69-72.

35 Ozdemir AO, Tamayo A, Munoz C, Dias B, Spence JD. Cryptogenic stroke and patent foramen ovale: clinical clues to paradoxical embolism. J Neurol Sci. 2008 Dec;275(1-2):1217.

36 Prefasi D, Martínez-Sánchez P, Fuentes B, Díez-Tejedor E. The utility of the RoPE score in cryptogenic stroke patients $\leq 50$ years in predicting a stroke-related patent foramen ovale. Int J Stroke. 2016 Jan;11(1):NP7-8.

37 Wessler BS, Kent DM, Thaler DE, Ruthazer R, Lutz JS, Serena J. The RoPE Score and Rightto-Left Shunt Severity by Transcranial Doppler in the CODICIA Study. Cerebrovasc Dis. 2015;40(1-2):52-8. 
38 Braemswig TB, Usnich T, Scheitz JF, Erdur H, Fiebach JB, Audebert HJ, et al. Early Recurrent Ischemic Lesions in Patients With Cryptogenic Stroke and Patent Foramen Ovale: An Observational Study. Front Neurol. 2018 Nov;9:996.

39 Thaler DE, Ruthazer R, Weimar C, Mas JL, Serena J, Di Angelantonio E, et al. Recurrent stroke predictors differ in medically treated patients with pathogenic vs. other PFOs. Neurology. 2014 Jul;83(3):221-6.

40 Rana BS, Thomas MR, Calvert PA, Monaghan MJ, Hildick-Smith D. Echocardiographic evaluation of patent foramen ovale prior to device closure. JACC Cardiovasc Imaging. 2010 Jul;3(7):749-60.

41 Katsanos AH, Psaltopoulou T, Sergentanis TN, Frogoudaki A, Vrettou AR, Ikonomidis I, et al. Transcranial Doppler versus transthoracic echocardiography for the detection of patent foramen ovale in patients with cryptogenic cerebral ischemia: A systematic review and diagnostic test accuracy meta-analysis. Ann Neurol. 2016 Apr;79(4):625-35.

42 Kasner SE, Swaminathan B, Lavados P, Sharma M, Muir K, Veltkamp R, et al.; NAVIGATE ESUS Investigators. Rivaroxaban or aspirin for patent foramen ovale and embolic stroke of undetermined source: a prespecified subgroup analysis from the NAVIGATE ESUS trial. Lancet Neurol. 2018 Dec;17(12): 1053-60.

43 Agarwal S, Bajaj NS, Kumbhani DJ, Tuzcu EM, Kapadia SR. Meta-analysis of transcatheter closure versus medical therapy for patent foramen ovale in prevention of recurrent neurological events after presumed paradoxical embolism. JACC Cardiovasc Interv. 2012 Jul; 5(7):777-89.

44 Kitsios GD, Dahabreh IJ, Abu Dabrh AM, Thaler DE, Kent DM. Patent foramen ovale closure and medical treatments for secondary stroke prevention: a systematic review of observational and randomized evidence. Stroke. 2012 Feb;43(2):422-31.

45 Mas JL, Derumeaux G, Guillon B, Massardier $\mathrm{E}$, Hosseini $\mathrm{H}$, Mechtouff $\mathrm{L}$, et al.; CLOSE Investigators. Patent Foramen Ovale Closure or Anticoagulation vs. Antiplatelets after Stroke. N Engl J Med. 2017 Sep;377(11): 1011-21.

46 Orgera MA, O’Malley PG, Taylor AJ. Secondary prevention of cerebral ischemia in patent foramen ovale: systematic review and metaanalysis. South Med J. 2001 Jul;94(7):699703.

47 Kent DM, Dahabreh IJ, Ruthazer R, Furlan AJ, Weimar C, Serena J, et al. Anticoagulant vs. antiplatelet therapy in patients with cryptogenic stroke and patent foramen ovale: an individual participant data meta-analysis. Eur Heart J. 2015 Sep;36(35):2381-9.
48 Patti G, Pelliccia F, Gaudio C, Greco C. Metaanalysis of net long-term benefit of different therapeutic strategies in patients with cryptogenic stroke and patent foramen ovale. Am J Cardiol. 2015 Mar;115(6):837-43.

49 Sardar P, Chatterjee S, Wu WC, Lichstein E, Ghosh J, Aikat S, et al. New oral anticoagulants are not superior to warfarin in secondary prevention of stroke or transient ischemic attacks, but lower the risk of intracranial bleeding: insights from a meta-analysis and indirect treatment comparisons. PLoS One. 2013 Oct;8(10):e77694.

50 Hornung M, Bertog SC, Franke J, Id D, Taaffe $\mathrm{M}$, Wunderlich $\mathrm{N}$, et al. Long-term results of a randomized trial comparing three different devices for percutaneous closure of a patent foramen ovale. Eur Heart J. 2013 Nov; 34(43):3362-9.

51 Schwerzmann M, Windecker S, Wahl A, Mehta H, Nedeltchev K, Mattle H, et al. Percutaneous closure of patent foramen ovale: impact of device design on safety and efficacy. Heart. 2004 Feb;90(2):186-90.

52 Tsivgoulis G, Katsanos AH, Mavridis D, Frogoudaki A, Vrettou AR, Ikonomidis I, et al. Percutaneous patent foramen ovale closure for secondary stroke prevention: network meta-analysis. Neurology. 2018 Jul;91(1):e8-18.

53 Elgendy AY, Elgendy IY, Mojadidi MK, Mahmoud AN, Barry JS, Jneid H, et al. New-onset atrial fibrillation following percutaneous patent foramen ovale closure: a systematic review and meta-analysis of randomised trials. EuroIntervention. 2019 Apr;14(17):1788-90.

54 Bridges ND, Hellenbrand W, Latson L, Filiano J, Newburger JW, Lock JE. Transcatheter closure of patent foramen ovale after presumed paradoxical embolism. Circulation. 1992 Dec;86(6):1902-8.

55 Khairy P, O'Donnell CP, Landzberg MJ. Transcatheter closure versus medical therapy of patent foramen ovale and presumed paradoxical thromboemboli: a systematic review. Ann Intern Med. 2003 Nov;139(9):753-60.

56 Furlan AJ, Reisman M, Massaro J, Mauri L, Adams H, Albers GW, et al.; CLOSURE I Investigators. Closure or medical therapy for cryptogenic stroke with patent foramen ovale. N Engl J Med. 2012 Mar;366(11):991-9.

57 Meier B, Kalesan B, Mattle HP, Khattab AA, Hildick-Smith D, Dudek D, et al.; PC Trial Investigators. Percutaneous closure of patent foramen ovale in cryptogenic embolism. N Engl J Med. 2013 Mar;368(12):1083-91.

58 Carroll JD, Saver JL, Thaler DE, Smalling RW, Berry S, MacDonald LA, et al.; RESPECT Investigators. Closure of patent foramen ovale versus medical therapy after cryptogenic stroke. N Engl J Med. 2013 Mar;368(12):1092-100.

59 Saver JL, Carroll JD, Thaler DE, Smalling RW, MacDonald LA, Marks DS, et al.; RESPECT
Investigators. Long-Term Outcomes of Patent Foramen Ovale Closure or Medical Therapy after Stroke. N Engl J Med. 2017 Sep; 377(11):1022-32.

60 Søndergaard L, Kasner SE, Rhodes JF, Andersen G, Iversen HK, Nielsen-Kudsk JE, et al.; Gore REDUCE Clinical Study Investigators. Patent Foramen Ovale Closure or Antiplatelet Therapy for Cryptogenic Stroke. N Engl J Med. 2017 Sep;377(11):1033-42.

61 Lee PH, Song JK, Kim JS, Heo R, Lee S, Kim $\mathrm{DH}$, et al. Cryptogenic Stroke and High-Risk Patent Foramen Ovale: the DEFENSE-PFO Trial. J Am Coll Cardiol. 2018 May;71(20): 2335-42.

62 De Rosa S, Sievert H, Sabatino J, Polimeni A, Sorrentino S, Indolfi C. Percutaneous Closure Versus Medical Treatment in Stroke Patients With Patent Foramen Ovale: A Systematic Review and Meta-analysis. Ann Intern Med. 2018 Mar;168(5):343-50.

63 Shah R, Nayyar M, Jovin IS, Rashid A, Bondy BR, Fan TM, et al. Device Closure Versus Medical Therapy Alone for Patent Foramen Ovale in Patients With Cryptogenic Stroke: A Systematic Review and Meta-analysis. Ann Intern Med. 2018 Mar;168(5):335-42.

64 Ng PY, Ng AK, Subramaniam B, Burns SM, Herisson F, Timm FP, et al. Association of Preoperatively Diagnosed Patent Foramen Ovale With Perioperative Ischemic Stroke. JAMA. 2018 Feb;319(5):452-62.

65 Friedrich S, Ng PY, Platzbecker K, Burns SM, Banner-Goodspeed V, Weimar C, et al. Patent foramen ovale and long-term risk of ischaemic stroke after surgery. Eur Heart J. 2019 Mar;40(11):914-24.

66 Almekhlafi MA, Wilton SB, Rabi DM, Ghali WA, Lorenzetti DL, Hill MD. Recurrent cerebral ischemia in medically treated patent foramen ovale: a meta-analysis. Neurology. 2009 Jul;73(2):89-97.

67 Serena J, Marti-Fàbregas J, Santamarina E, Rodríguez JJ, Perez-Ayuso MJ, Masjuan J, et al.; CODICIA, Right-to-Left Shunt in Cryptogenic Stroke Study; Stroke Project of the Cerebrovascular Diseases Study Group, Spanish Society of Neurology. Recurrent stroke and massive right-to-left shunt: results from the prospective Spanish multicenter (CODICIA) study. Stroke. 2008 Dec;39(12):3131-6.

68 Katsanos AH, Spence JD, Bogiatzi C, Parissis J, Giannopoulos S, Frogoudaki A, et al. Recurrent stroke and patent foramen ovale: a systematic review and meta-analysis. Stroke. 2014 Nov;45(11):3352-9.

69 Morais LA, Sousa L, Fiarresga A, Martins JD, Timóteo AT, Monteiro AV, et al. RoPE Score as a Predictor of Recurrent Ischemic Events After Percutaneous Patent Foramen Ovale Closure. Int Heart J. 2018 Nov;59(6):132732. 